\title{
A mediação das TDIC na constituição da subjetividade espaço/temporal em estudantes do Ensino Médio.
}

\author{
Ana Maria de Oliveira Pereira \\ Universidade FEEVALE - PPG Diversidade Cultural e Inclusão Social - Novo \\ Hamburgo RS. \\ anamaria.oliveira08@gmail.com
}

\begin{abstract}
Resumo - Este texto é parte da reflexão teórica acerca da importância do uso das tecnologias digitais nas aulas de Geografia como potencializador da constituição da subjetividade espaço temporal, que estamos desenvolvendo em pesquisa de doutorado. Realizamos um panorama referente ao acesso às tecnologias nas escolas brasileiras a partir da interpretação dos dados da pesquisa TIC Educação 2014. Abordaremos a relação sociedade de consumo e as tecnologias, bem como uma possibilidade de uso das tecnologias digitais nas aulas de Geografia. Por fim as considerações referentes à constituição da subjetividade espaço temporal dos estudantes e a condição de protagonista social e não somente inserido ao meio.
\end{abstract}

\begin{abstract}
This text is a part of the theoretical reflection about the importance of the use of digital technologies in Geography teaching potentiating the constitution of the timeline subjectivity, which we are developing in the doctoral research. We conducted a scenery regarding the access to technologies in Brazilian schools through the interpretation of the TIC Educação 2014 research information. We will be approaching the relation between the consumer's society and technologies, as well as the possibilities of using digital technologies while teaching Geography. Finally, the considerations related to the students' constitution of the timeline subjectivity and the posture of social leading figure and not only inserted in the environment.
\end{abstract}

\subsection{Introdução}

Muitas vezes as disciplinas escolares parecem estar desconectadas do cotidiano dos estudantes. A Geografia é uma delas e apesar de ter um caráter bastante dinâmico, pois estuda a complexa relação sociedade natureza, ainda utilizam-se muitos recursos de memorização nas aulas em detrimento de outros como mapas, globos, fotos de satélite, GPS e programas disponíveis na internet para a construção do conhecimento geográfico. 
Proporcionar condições aos estudantes para que os mesmos possam associar os conteúdos vistos na escola ao seu dia a dia é tornar a aprendizagem significativa, se assim for, contribuirá para que o mesmo tenha maiores e melhores condições de entender a sociedade e sentir-se parte integrante da mesma. Podendo desfrutar e também preservar o que está no seu entorno.

A convivência em ambiente que estimule construções significativas acerca dos conteúdos escolares contribui para a constituição da subjetividade que vai acompanhar o indivíduo para além da sua vida na escola. Dessa forma, na constituição da subjetividade o indivíduo terá mais ou menos associações, conforme o estímulo que o mesmo tiver do meio em que ele está inserido, neste caso, o espaço escolar.

A desigualdade permeia as relações sociais e na escola é possível ver essa questão de maneira mais acentuada, pois, os estudantes, provenientes de grupos sociais diversos frequentam o ambiente escolar com o propósito de sentirem-se inclusos na sociedade letrada. Porém, será que este espaço está proporcionando de maneira ampla e igualitária essa condição?

Neste artigo procura-se fazer um paralelo entre os objetivos do ensino de Geografia no Ensino Médio e o uso das tecnologias digitais como recurso pedagógico que tem condições de auxiliar no processo de construção do conhecimento geográfico levando ao entendimento da sociedade em que se está inserido. Neste sentido, faremos também uma discussão sobre a importância de conhecer os recursos digitais que permeiam a nossa vida para poder entender a lógica do consumo que está imbricada a utilização dos mesmos e a falsa sensação de inclusão que se desenvolve pela aquisição de bens.

Realizamos um estudo de abordagem qualitativa de cunho exploratório descritivo com pesquisa bibliográfica, para evidenciar o atual cenário brasileiro no que se refere ao acesso e uso das TDIC pelos estudantes da educação básica, em atividades de aula.

\subsection{As Ciências Humanas e suas Tecnologias: reflexões sobre a Geografia no Ensino Médio e o acesso dos estudantes às TIC.}

Nos Parâmetros Curriculares Nacionais (PCNs) [2000, p.11] o componente curricular Geografia faz parte da grande área Ciências Humanas e suas tecnologias, juntamente com História, Sociologia e Filosofia os quais têm como objetivos proporcionar condições para que os estudantes se apropriem de mecanismos que os levem a "compreender os elementos cognitivos, afetivos, sociais e culturais que constituem a identidade própria e a dos outros".

Neste contexto, a Geografia tem papel importante na constituição da subjetividade dos estudantes do ensino médio, visto que ha muito tempo perdeu seu caráter descritivo e simplificador dos aspectos físicos da Terra e do homem. As aulas de Geografia são muito mais do que memorização de informações soltas sobre relevo, 
clima, vegetação, rios e população. Estas informações necessitam contextualização acerca de sua importância para o entendimento do espaço geográfico, definido por Milton Santos como o "resultado da conjugação entre sistemas de objetos e sistemas de ações" [2009, p.100], ou seja, a ação do homem (sociedade) no espaço. Essa ação difere-se em cada momento histórico da sociedade conforme suas necessidades.

Para entender esta complexa rede, é necessário que se proporcione ao estudante condições para que o mesmo possa construir conhecimento acerca da sociedade em que está inserido e ter condições de intervenção na mesma. Para tanto, dentro dos estudos da Geografia é fundamental o entendimento de que o espaço geográfico é composto de materialidade (natural e construída) e de relações sociais, políticas, econômicas e culturais. Por isso, a importância de trabalhar os conceitos de espaço, território, sociedade e paisagem.

Estes conceitos são trabalhados em toda e educação básica e é no ensino médio que acontece o maior entendimento acerca da inter-relação deles. Isso devido ao arcabouço de conteúdos, sua sistematização e interpretação, conforme as fases de desenvolvimento cognitivo, proporcionados nos anos anteriores. Tal processo tem como propósito a utilização desses conceitos pelos estudantes, para que possam despertar o sentimento de inclusão e pertencimento ao meio em que está inserido protagonizando sua participação na sociedade.

\subsection{A realidade brasileira quanto a uso e acesso das TDIC nas escolas}

Com o intuito de proporcionar condições de utilização das TIC em sala de aula o governo federal cria o ProInfo $^{1}$, tal programa também contempla a formação de professores para utilização das tecnologias em atividades escolares. Já se passaram alguns anos da criação do programa, outros já foram criados, quem sabe outros ainda virão e o efetivo uso das tecnologias digitais em atividades pedagógicas ainda anda em passos lentos. Isso por que, "além da escola possuir equipamentos adequados, é necessário que ela tenha um quadro de professores capacitado para lidarem com as TDIC” [FIGUEIREDO, NOBRE e PASSOS, 2015 p. 129]

Para este trabalho, optamos por utilizar dados da Pesquisa anual realizada pelo Centro Regional de Estudos para o Desenvolvimento da Sociedade da Informação (Cetic.br) ligado ao Comitê Gestor da Interne do Brasil (CGI.br).A pesquisa TIC Educação 2014, divulgada em Junho de 2015, nos dá um parâmetro da atual situação de uso das TDIC em atividades na escola. No item "proporção de escolas com acesso a internet $^{2 \%}$, das 903 escolas pesquisadas ( públicas e privadas) constata-se que $97 \%$

\footnotetext{
${ }^{1}$ ProInfo - Programa Nacional de Tecnologia Educacional - Portaria n ${ }^{\circ}$ 522/MEC, de 9 de abril de 1997 - É um programa educacional com o objetivo de promover o uso pedagógico da informática na rede pública de educação básica.

O programa leva às escolas computadores, recursos digitais e conteúdos educacionais. Em contrapartida, estados, Distrito Federal e municípios devem garantir a estrutura adequada para receber os laboratórios e capacitar os educadores para uso das máquinas e tecnologias. Disponívem em: http://portal.mec.gov.br/index.php?Itemid=462 - consultado em 20.04.2016.

${ }^{2}$ http://cetic.br/tics/educacao/2014/escolas/D10/
} 
possuem acesso, sendo que, nas Regiões Centro Oeste e Sul encontram-se o maior número de escolas conectadas a internet.

$\mathrm{Na}$ análise dos dados apresentados pela pesquisa é possível perceber, que ainda existem desigualdades de acesso à internet entre as regiões, porém ao compararmos dados obtidos pela mesma pesquisa realizada em $2011^{3}$ é possível constatar que está havendo um crescimento no que diz respeito à conexão com a internet nas escolas públicas brasileiras. Resultado das políticas públicas que tem a informática nas escolas como objetivo, porém o caminho ainda é longo.

Analisamos também os itens: alunos que utilizaram computadores: os que já utilizaram a internet e por fim a tabela onde aparece a percepção dos alunos por atividades desenvolvidas com o auxilio do computador.

No item alunos que utilizam comuptadores, conforme dados da pesquisa ${ }^{4}$, dos 9.532 alunos entrevistados, $95 \%$ já utilizaram computador, destacando-se também as regiões Sul e Centro Oeste coma as que possuem maior número de alunos nesta condição. Já a região Nordeste o menor índice, 90\%. Do mesmo total de entrevistados, 93\% já utilizaram a internet ${ }^{5}$, ou seja, além de já terem tido contato com o suporte, neste caso o computador, conhecem também a rede (internet). Nas percepções dos alunos acerca das atividades realizadas com o auxilio do computador ${ }^{6}$, analisamos as respostas obtidas nos itens: uso de programa multimídia, som e imagem; copiar ou mover um arquivo ou uma pasta e escrever utilizando um editor de texto. Do total de entrevistados, $38 \%$ não possuem nenhuma dificuldade para realizar a atividade, já $19 \%$ nunca usou programa multimídia. Para copiar ou mover arquivos e pastas 39\% não apresentam dificuldades e $16 \%$ não realizam a atividade. Por fim o percentual de quem não tem dificuldades com o editor de texto é de $41 \%$ e os que não realizam a atividade é de $15 \%$

Optou-se pela utilização dos dados desta pesquisa, pois são informações atualizadas anualmente acerca da utilização das TDIC nas escolas brasileiras e também por entendermos que estes itens especificamente, contribuem com a reflexão que estamos tecendo sobre utilização das TDIC em atividades escolares como contribuição para a inclusão social e não somente inclusão e/ou aceitação em comunidades, que veremos no próximo item.

Nas informações analisados é possível perceber que a grande maioria dos estudantes entrevistados, já utilizaram o computador e também a internet, sendo que, o maior percentual dos que não utilizaram está na região Nordeste. Isso nos leva ao entendimento de apesar do percentual estar crescendo se compararmos com pesquisas anteriores, ainda existem muitos estudantes que não tem contato com as TDIC em suas atividades nas escolas.

Já na análise das percepções dos estudantes quanto à utilização dos recursos disponíveis nas TDIC, observa-se que ainda é grande o percentual de estudantes que

\footnotetext{
${ }^{3}$ Disponível em: http://www.cetic.br/

${ }^{4}$ Tabela disponível em: http://cetic.br/tics/educacao/2014/alunos/B1/

${ }^{5}$ Tabela disponível em: http://cetic.br/tics/educacao/2014/alunos/B3/

${ }^{6}$ Tabela disponível em : http://cetic.br/tics/educacao/2014/alunos/C1A/
} 
possuem dificuldades no uso das ferramentas disponíveis nas tecnologias digitais, principalmente quando as atividades exigem criação, elaboração e reflexão. Embora a utilização dos recursos focados na pesquisa, para coleta de dados, serem de uso fácil, os estudantes ainda possuem alguma dificuldade, pois é necessário o conhecimento de mais recursos e também de autonomia do mesmo para criação. Essa criação pode levar a construção do conhecimento referente ao conteúdo que esta sendo trabalhado em aula, imbricado à utilização das TDIC, porém, não sem a mediação pedagógica do professor, que é quem proporcionará ao estudante as interpretações acerca do assunto.

\section{3 - Inclusão social ou Inclusão a comunidades de consumo? Como a utilização das TDC nas aulas de Geografia do Ensino Médio podem contribuir para encontrar essa resposta?}

Vivemos na sociedade de consumo, na qual somos vorazes consumidores, isso devido ao protagonismo das tecnologias digitais que disseminam informações e possibilitam a criação de necessidades globalizadas. Essa sociedade, também conhecida como "sociedade sem fio", [BAUMAN, 2008, p.7] por estar permanentemente conectada em diversos suportes tais como: celulares, tabletes, notebooks e outros, ao mesmo tempo em que nos desterritorializa e reterritorializa dando a impressão de supressão do espaço/tempo, produz grandes desigualdades e consequentemente comunidades, onde pessoas solicitam a participação gerando assim uma sensação de inclusão nesse espaço.

Conforme Baumam, "comunidade é uma versão compacta de estar junto, e de um tipo de estar junto que nunca ocorre na vida real" [2001, p. 127] principalmente em se falando do momento histórico que estamos vivendo, onde o ter é mais importante que o ser, onde as pessoas que pertencem à mesma comunidade virtual em redes sociais não se conhecem presencialmente.

O sentimento que permeia a sociedade é que sempre se tem necessidade de alguma coisa e quando esse bem é adquirido, outras necessidades se tornam imprescindíveis. Porém esse fato não gera uma desilusão, conforme Bauman:

Para os consumidores da sociedade de consumo, estar em movimentoprocurar, buscar, não encontrar ou, mais precisamente, não encontrar ainda não é sinônimo de mal-estar, mas promessa de bem-aventurança, talvez a própria bem-aventurança. [BAUMAN 1999, p. 91]

Se por um lado a evolução tecnológica proporciona a necessidade de consumo, por outro ela também pode proporcionar melhores condições de aprendizagens. Além da visualização os recursos tecnológicos disponíveis apresentam condições de comparação de informações e dados de espaços e tempos distintos e, a partir da mediação pedagógica do professor, neste caso, de Geografia, a interpretação desses dados e sua importância na construção do conhecimento geográfico e para a vida em sociedade. 
Alguns recursos disponíveis nas TDIC são potencializadores da construção do conhecimento geográfico, pois proporcionam a visualização de espaços, próximos ou distantes, com informações visuais possíveis e passíveis de interpretação acerca das mudanças e ações da sociedade no mesmo. Ações estas que podem proporcionar desterritorializações, reterritorializações e novas territorialidades as quais influenciam na constituição da subjetividade espaço/temporal dos indivíduos.

\subsection{Possibilidades de uso de recursos disponíveis nas TIC em aulas de Geografia da Educação Básica.}

A evolução do meio técnico/científico contribuiu e continua contribuindo muito para os estudos da Geografia. O sensoriamento remoto e a informática são ferramentas que auxiliam na construção dos Sistemas de Informação Geográfica (SIG), os quais proporcionaram grandes mudanças na forma de analisar o espaço geográfico. Esses recursos são utilizados nos cursos de formação inicial dos professores de Geografia, porém nem sempre se estende a utilização aos estudantes da educação básica, por diversos motivos que não são objeto de estudo desse artigo. Aqui procuraremos dissertar sobre as possibilidades de utilização de uma ferramenta disponível na rede, ( internet) conhecida como tecnologia de rede (TR) que pode contribuir para a constituição da subjetividade nos estudantes do ensino médio no que diz respeito ao espaço/ tempo.

A utilização da tecnologia, Google Earth $^{7}$ nas aulas de Geografia do ensino médio além de possibilitar visualização do ambiente estudado, "com possibilidade de aproximação e distanciamento, sobrevoo, observação de edificações, algumas em 3D" [PEREIRA e TEIXEIRA, 2010, pág. 53] e também em datas diferentes permite a visualização das transformações ocorridas nos últimos anos nos diferentes espaços geográficos. Dessa maneira, as condições de interpretação e possíveis intervenções podem potencializar-se, porém essa atividade terá êxito se houver uma mediação que leve a esse entendimento. Neste sentido, destaca-se o papel do professor de Geografia o qual irá proporcionar condições para que o estudante construa o conhecimento em relação ao tema estudado e a ferramenta utilizada.

Nas figuras a seguir demonstra-se uma possibilidade de uso da tecnologia citada, e suas possíveis interpretações. Neste caso utilizou-se um regulador de tempo, disponível no próprio programa, para mostrar a paisagem em épocas distintas 1973 e 2014. Dessa maneira é possível fazer a análise da paisagem e as mudanças que ocorreram no período, permitindo a partir da visualização, a construção do conhecimento geográfico, o entendimento das mudanças ocorridas no decorrer do tempo, bem como a problematização dos objetivos econômicos e sociais do espaço nos diferentes tempos.

\footnotetext{
${ }^{7}$ Programa gratuito disponível para download, porém para sua atualização é necessário conexão com a internet.
} 
V Congresso Brasileiro de Informática na Educação (CBIE 2016)

Anais do XXII Workshop de Informática na Escola (WIE 2016)

Figura 01 - Mar de Aral em 1973

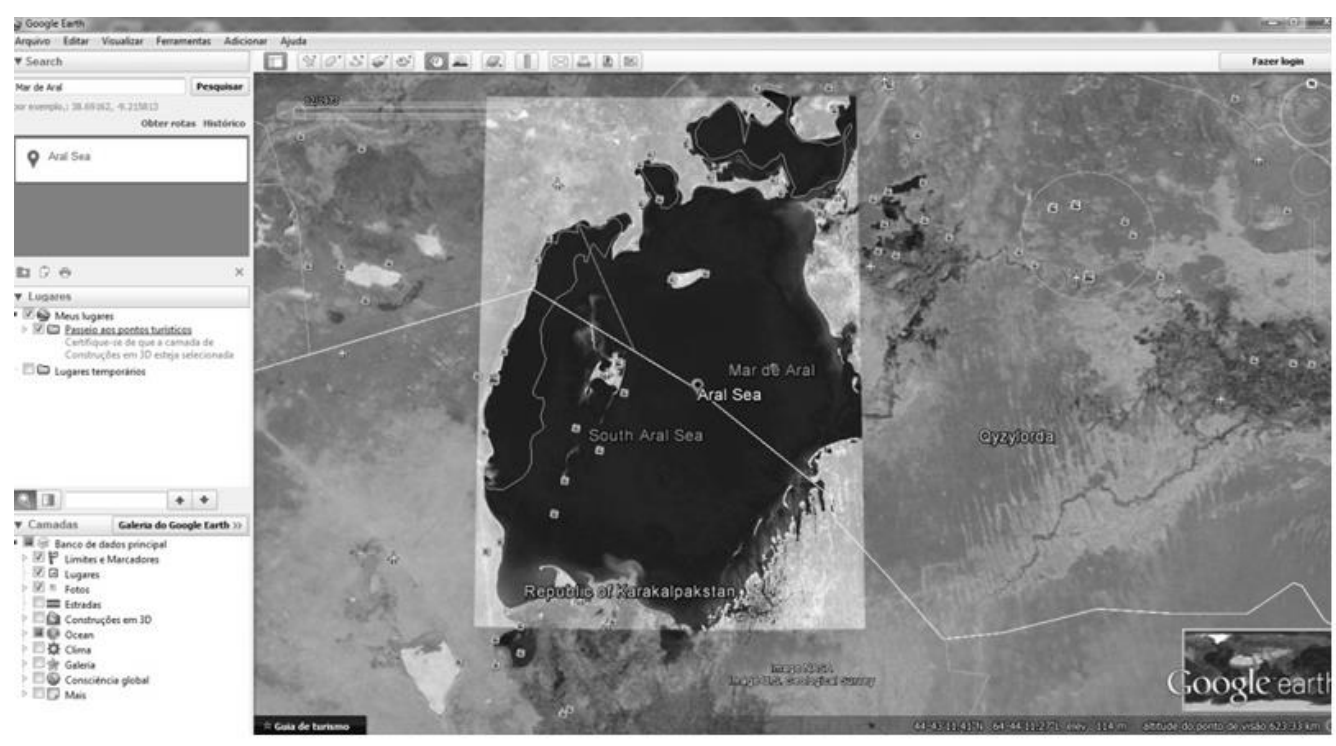

Fonte: Google Earth - Dezembro 2014

Figura 02 - Mar de Aral em 2014

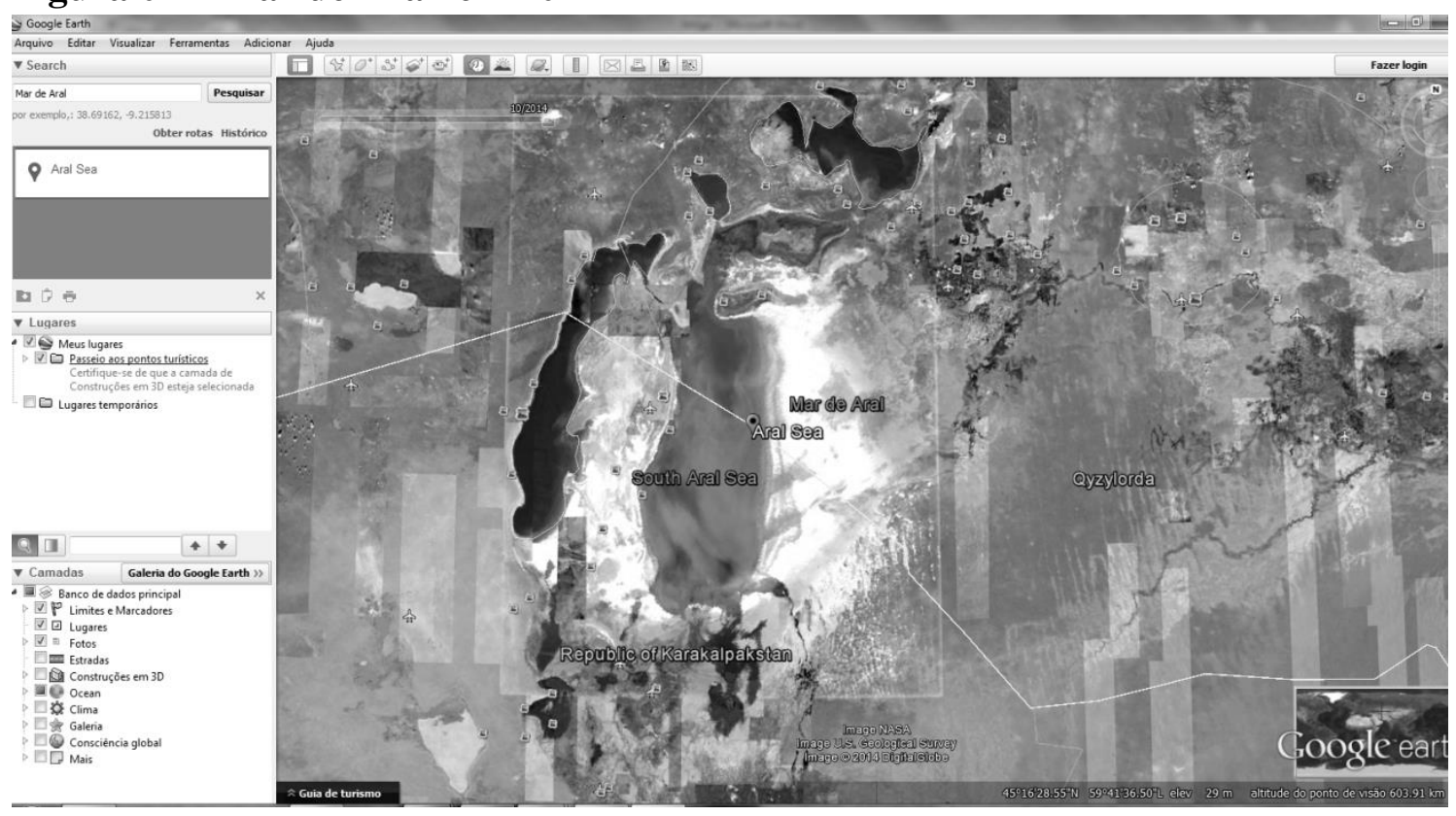

Fonte: Google Earth - Dezembro 2014 
A região escolhida, Mar de Aral, localizado na Ásia, entre o Cazaquistão e Uzbequistão é um grande lago de água salgada que nos últimos anos vem passando por grande transformação física, como pode ser visto através das figuras 01 e 02.

A partir da utilização do programa existe a possibilidade de interpretação das alterações vistas nas figuras, através de outras fotos em diferentes épocas que também podem ser postadas pelos usuários do programa bem como a pesquisa de informações acerca do porque da mudança que tem origem no processo de desenvolvimento econômico da região.

Salienta-se a partir da observação das figuras 01 e 02, a importância da mediação pedagógica do professor, pois a interpretações das informações obtidas com o auxilio das TDIC não acontecem de maneira natural, necessitam, problematização, ou seja, condições para que possam ser assimiladas, compreendidas e terem sentido para o estudante.

As possibilidades de desenvolvimento do sentimento de pertença ao espaço acontecerão a partir do momento em que o estudante conhecer e entender o espaço no qual está inserido. Para isso é de singular importância que se utilizem as tecnologias disponíveis para viabilizar a construção do conhecimento nas instituições de ensino formal.

O entendimento de que existem outros espaços, de que é possível encurtar o tempo de deslocamento de pessoas, notícias e materiais, de que as transformações acontecem, de que acontecimentos em locais muito distantes podem repercutir em nossa vida, se efetiva a partir das construções realizadas pelos indivíduos e as condições que o meio lhe proporciona. A escola como espaço de inclusão social, ou ao menos deveria ser, precisa pautar suas ações para proporcionar condições ao estudante de constituição da subjetividade espaço/temporal permeada pelos recursos tecnológicos já existentes e possíveis de serem utilizados em atividades regular de ensino/aprendizagem.

\subsection{Considerações Finais}

Para a psicologia não é com o nascimento da um bebê que nasce um sujeito. O sujeito se constitui a partir de suas relações no espaço social onde está inserido e a subjetividade vai sendo constituída a partir do afastamento que o sujeito tem da mãe ou de quem ocupa o lugar materno. Assim, quando o sujeito vai para escola, já possui na sua subjetividade o resultado das relações do meio em que vive, e é na educação formal que dará continuidade a construção da mesma, que estará sujeita as interferências do meio.

A sociedade contemporânea é permeada pelas tecnologias digitais, porém o acesso a elas não é uniforme a todos os sujeitos. Assim, entende-se que o mecanismo que tem potencialidade de inclusão social, muitas vezes gera uma grande exclusão, ou, conforme Boaventura de Sousa Santos [2006] uma inclusão subordinada, onde as políticas compensatórias mentem os níveis de desigualdade conforme a necessidade do capital no momento. 
Dentre as políticas educacionais do estado estão os investimentos na educação básica, como a formação de professores e a informatizaçãa ${ }^{8}$ das escolas. Neste sentido, vislumbra-se um cenário de possibilidades para a utilização das TDIC nas atividades em sala de aula como mecanismo emancipador e mediador na construção do conhecimento do qual destaca-se neste texto, o conhecimento geográfico.

Proporcionar condições para que os indivíduos construam entendimento a cerca da sociedade em que estão inseridos e sintam-se pertencentes a ela também é papel da escola. É nesse espaço, pela interação com os colegas, professores e com o conhecimento que irá acontecer à constituição da subjetividade do sujeito. E o mesmo terá maiores ou menores condições de interpretação e protagonismo no meio em que vive dependendo das condições que lhes foram proporcionadas.

Dessa maneira, entende-se que proporcionar inclusão social é também proporcionar condições para que os indivíduos sintam-se além de inseridos ao meio, protagonistas no mesmo, com condições para contestar, dar opinião ou realizar mudanças no espaço. Portanto, acredita-se que a utilização das tecnologias digitais nas escolas, inseridos nas atividades regulares das disciplinas, explorando os recursos disponíveis nelas podem potencializar a inclusão social deixando para trás a condição de inserido ao meio e dando espaço para o papel de protagonista no meio.

\subsection{REFERÊNCIAS}

BAUMAN, Zygmunt. (1999) Globalização: as consequências humanas. Rio de Janeiro: Zahar.

. (2001) Modernidade Liquida. Rio de Janiero: Zahar. (2008) Vida para Consumo. Rio de Janeiro: Zahar.

FIGUEIREDO, Gislaine Lourenço Rocha. NOBRE. Isaura Alcina Martins, PASSOS Marize Lyra Silva. (2015) Tecnologias Computacionais na Educação: Desafios na Prática Docente. CBIE-LACLO 2015. Anais do XXI Workshop de Informática na Escola (WIE 2015) Maceió - AL. Anais, p. 127 a 136. Disponível em: http://www.br-ie.org/pub/index.php/sbie

CGI, TIC Educação 2014. São Paulo, SP: Comitê Gestor da Internet no Brasil, 2015.Disponível em: http://cetic.br/pesquisa/educacao/ . Acesso em 19 de Março de 2016.

GOOGLE EATYH. Software Google Earth. Disponível em: http://www.google.com.br/intl/pt-BR/earth/ . Acesso em 20 Março 2016. MINISTÉRIO DA EDUCAÇÃO E CULTURA. Lei De Diretrizes E Bases Da Educação Nacional. Disponível em http://portal.mec.gov.br/arquivos/pdf/ldb.pdf. Acesso em 23 de Março de 2016.

\footnotetext{
${ }^{8}$ Entende-se por informatização neste texto, os laboratórios de informática disponíveis nas escolas, os tablets e os laptops utilizados pelos alunos e professores, bem como o acesso a internet por banda larga.
} 
V Congresso Brasileiro de Informática na Educação (CBIE 2016)

Anais do XXII Workshop de Informática na Escola (WIE 2016)

PEREIRA, Ana M. O. TEIXEIRA, Adriano C. ( 2010) O Potencial das Tecnologias de Rede na Construção do conhecimento Geográfico. Dissertação de Mestrado. PPGEDU - $\quad$ UPF. $2010 . \quad$ Disponível em https://secure.upf.br/tede/tde_busca/arquivo.php?codArquivo $=422$

REY, Fernando L.G. ( 2005) Pesquisa Qualitativa em psicologia: caminhos e desafios. São Paulo: Pioneira Thomson Learning.

SANTOS, Boaventura de S. ( 2006) A Gramática do Tempo: para uma nova cultura política. São Paulo: Cortez.

SANTOS, Milton.( 2009) A natureza do Espaço. São Paulo: Edusp. 